\title{
El humanismo es una violencia propia de bestias. Filosofando a martillazos, a partir de Levinas y Derrida, la medida de lo humano y lo humano como medida 1
}

\section{Humanism is a violence typical of the beasts. Philosozing with a Hammer, using Levinas and Derrida, the Measure of the Human and the Human as a measure}

\author{
Jorge León y Julia Urabayen \\ Universidad San Jorge (Zaragoza) y ICS Universidad de Navarra
}

Recibido: 31-10-2014

Aceptado: 07-09-2015

Lo que en realidad es grave y amenaza la civilización no es el matar a un hombre por sus ideas (se lo ha hecho a menudo en tiempos de guerra), sino hacerlo sin confesárselo y sin decirlo, poner sobre la justicia revolucionaria la máscara del Código Penal. $^{2}$

\section{Resumen}

La reflexión levinasiana surge como una crítica a la filosofía tradicional que, al estar basada en la presencia y la identidad, conduce a la exclusión del otro. Frente

\footnotetext{
1 Este artículo recoge resultados de la investigación "Mapa de Riesgo Social" financiada por el Ministerio de Economía y Competitividad, Programa de I+D+I orientada a los Retos de la Sociedad, 2013. Referencia: CSO2013-42576-R.

2 Merleau Ponty, M., Humanismo y Terror, Buenos Aires, La Pléyade, p. 78. El problema de la medida, eje de este artículo, se destaca muy bien en el siguiente fragmento: "La nación central [...] será más que nación, será civilización; será mejor que civilización, será familia. Unidad de lengua, unidad de moneda, unidad de medida, unidad de meridiano, unidad de código [...] Esta nación tendrá como
} 
a un pensar onto-lógico, el lituano propone que la ipseidad del ser humano sea constituida por la alteridad, y lo sea éticamente, porque el sujeto es sujeto-a, es decir, responsabilidad. En un intento por llevar aún más allá la obligada atención a la otredad del otro, Derrida desarrollará una crítica radical a la postura levinasiana. Deconstrucción de todo rastro de ipseidad y soberanía en la relación con el otro, la lectura de la obra de Derrida aquí realizada apuesta por una concepción no definible de lo humano. De ahí que toda de-limitación de un ámbito ético como propiamente humano conlleve una violencia bestial que el levinasiano humanismo del otro pretendía superar.

Palabras clave: Levinas, Derrida, alteridad, heteronomía, otredad, bestialidad.

\section{Abstract}

Levinas's reflections arose as a critique of traditional philosophy which, since it was based on presence and identity, leads to the exclusion of the other. Instead of an onto-logical thought the Lithuanian proposes that the ipseity of the human being be constituted by alterity, and that it be so ethically, because the subject is sub-ject, that is, that which upholds, responsibility. In an attempt to take the obligatory attention to the otherness of the other even further, Derrida would develop a radical critique of the Levinasian posture. Deconstruction of every trace of ipseity and sovereignty in the relationship with the other, the reading that we have done of the work of Derrida opts for a no definable understanding of the human. That is why every de-limitation of an ethical field as a properly human implies a brutal violence that the levinasian humanism of the other tried to exceed.

Keywords: Levinas, Derrida, Alterity, Heteronomy, Otherness, Bestiality.

En 1947 Merleau Merleau Ponty advertía que "el humanismo, cuando quiere realizarse rigurosamente, se transforma en su contrario, es decir, en violencia" 3 . La postura de Merleau Ponty, paradójicamente cercana al liberalismo rortyano de la inconmensurabilidad de los lenguajes con los que describimos el mundo 4 , en su afán por comprender los procesos de Moscú, se apoyaba en una concepción de la revolución que "no define al delito de acuerdo con el derecho establecido, sino de

capital París, y no se llamará Francia, se llamará Europa. Se llamará la Europa del siglo XX, y, en los siglos siguientes, todavía más trasfigurada, se llamará Humanidad”, Víctor Hugo citado en Derrida, J., Políticas de la amistad, Madrid, Trotta, p. 296. (El subrayado es nuestro).

3 Merleau Ponty, M., Humanismo y Terror, p. 57.

4 Para un mayor conocimiento del liberalismo pragmatista de corte rortyano y de los intentos de concebir una posición política de la deconstrucción a partir de la ética levianasiana remitimos a Mouffe, Ch. (ed.), Deconstruction and pragmatism, London and New York, Routledge, 1996. 
acuerdo con el de la sociedad que quiere crear"5. De este modo, el filósofo francés consideraba que "los procesos de Moscú son de forma y de estilo revolucionarios. Pues ser revolucionario es juzgar lo que existe en nombre de lo que todavía no existe, tomándolo como más real que lo real" 6 . En última instancia, lo que el humanismo revolucionario pontyano rechazaba es la concepción de una justicia intemporal a favor de una justicia siempre contingente, inmersa en la violencia de la historia, en la que "la contingencia del porvenir que explica las violencias del poder, le quita al mismo tiempo toda legitimidad, o legitima igualmente la violencia de los opositores"7.

Se trata, en suma, de una reelaboración del humanismo que introduciendo la contingencia del porvenir como elemento de toque que permitiera sacar los discursos humanistas de la lógica de la presencia propia de sus formas más ilustradas, termina justificando nuevamente la violencia, esta vez desde un à venir propio de las estructuras revolucionarias. Se llega de este modo a un punto crítico del discurso humanista -ya sea entendido desde la ontología de la presencia, ya lo sea desde el à venir revolucionario-, cuyo significado político está abocado a convertirse en un discurso legitimante de la exclusión de todo aquel que no cumpla con los requisitos con los que se define lo propio del humano, bien en el presente o bien en el futuro ${ }^{8}$.

Tomando como referencia esta relación entre humanismo y violencia presentada por Merleau Ponty, y a diferencia de las propuestas de Lacou Labarthe y Jean Luc Nancy, la lectura que aquí queremos delinear no es tanto una problematización del totalitarismo como consecuencia de la absoluta transparencia e inmanencia de las comunidades políticas, sino como consecuencia del empleo de lo humano como autodefinición de uno mismo y exclusión de la otredad, Declaración Universal de los Derechos Humanos incluida9.

Desde este punto de vista, la lectura levinasiano-derrideana que aquí proponemos se dirige precisamente a mostrar que esta estructura de violencia y terror propia de todo humanismo, esta economía intelectual de la violencia, únicamente

\footnotetext{
5 Merleau Ponty, M., Humanismo y Terror, p. 26.

${ }^{6}$ Merleau Ponty, M., Humanismo y Terror, p. 71.

7 Merleau Ponty, M., Humanismo y Terror, p. 30. A este propósito, continuaba Merleau Ponty afirmando que "la idea de una justicia objetiva está desprovista de sentido, puesto que debería comparar conductas que se excluyen y entre las cuales la sola razón no bastaba para elegir [...] Aquí se muestra una dura idea de la responsabilidad, que no es lo que los hombres han querido, [sino] lo que descubren haber hecho a la luz de los acontecimientos", Merleau Ponty, M., Humanismo y Terror, p 87. 8 De forma paralela, esta será la crítica conjunta realizada por Simon Critchley, Ernesto Laclau y el propio Derrida al liberalismo de Rorty visto como lenguaje excluyente de todo aquel que pretende oponerse al lenguaje propuesto por el liberalismo. A este respecto ver Mouffe, Ch. (ed.), Deconstruction and pragmatism.

${ }^{9}$ En este sentido afirma Zizek que "la verdad de los derechos humanos universales son los derechos del comercio y de la propiedad privada”, Zizek, S., Repetir Lenin, Akal, Madrid, 2004, p. 166.
} 
puede ser comprendida dentro de una deconstrucción del entendimiento de lo humano en tanto que mediación conceptual utilizada para la delimitación, esto es, medida, exclusión y cierre de lo político como ajeno a una praxis del hombre con una realidad previa no-humana. En otras palabras, intentaremos mostrar, utilizando para ello un lenguaje levinasiano-derrideano, que la definición de lo político en tanto que ámbito de la decisión, y no como praxis intersubjetiva y mediación técnica, es una de las principales causas que ha propiciado la construcción del concepto de lo humano como estrategia de exclusión de la otredad. Para ello nos serviremos, en primer lugar, de las críticas realizadas por Levinas a las nociones de "sujeto" y de "persona", continuando, en segundo lugar, con la ulterior crítica derrideana al intento de definir un levinasiano humanismo del otro.

Esta elección es debida a que consideramos que las posturas de Levinas y Derrida suponen respuestas más radicales, con mayor fuerza de conmoción-desplazamiento de unos marcos conceptuales que, aunque estaban dañados y habían sido dinamitados previamente, todavía no habían sido demolidos. El envite al humanismo planteado por Levinas y Derrida requiere una salida de un clima y de un modo de entender la filosofía que, como no puede ser de otro modo, presupone la filosofía de Heidegger y su crítica a la onto-teología así como, al menos en el caso de Levinas, el existencialismo de Sartre ${ }^{10}$, pero va más allá en la búsqueda de una nueva comprensión del ser humano que no será más sujeto, soberano, ni autónomo, pero tampoco estará a la escucha del ser ni será su pastor.

La redefinición, reapropiación y desmontaje de las nociones que el humanismo ha asignado al ser humano se realizarán en estos pensadores franceses mediante un método hermenéutico que supondrá habitar el lenguaje para alcanzar el Decir, en el caso de Levinas, y el indecibidle, en el de Derrida. Por ello ambos filósofos apelarán a un método de raíz nietzscheana y, en igual medida, heideggeriana. Es decir, el recurso al lenguaje será el modo de traer a la presencia, de acceder a planos de sentido que no se encuentran encerrados en la pareja significado-significante, aunque están imbricados en cualquier acto lingüístico en el que hay un Decir y, con ello, un más allá del contenido ${ }^{11}$. Pero ese más allá no será entendible como un sujeto o

\footnotetext{
10 En el caso de Derrida, la influencia de Sartre sobre la construcción de su pensamiento no supone el mismo grado de intensidad que tiene en el pensador lituano. No es hasta la época tardía del pensamiento derrideano cuando el filósofo argelino dedica atención a las ideas del pensamiento sartreano, y siempre de forma lateral. Así, por ejemplo, no será hasta 2001 cuando Derrida consagre unas páginas a Sartre en las que le situará explícitamente "del lado del que denuncia el discurso sobre la fraternidad, el 'mito de la fraternidad' y del 'todos los hombre son hermanos' sostenido por 'la caridad burguesa"”, Derrida, J., Papel Máquina, Madrid, Editorial Trotta, 2003, pp. 148-149. Esto es, del lado de los críticos del humanismo clásico o tradicional.

11 En las primeras obras de Levinas la salida apunta más a la relación erótica y a la fecundidad que al lenguaje. Posteriormente Levinas apela al imperativo ético que funda toda racionalidad: la ética es anterior a la ontología. A partir del lenguaje, y no de la fecundidad, se puede hacer una metafísica que
} 
interlocutor constituido que se comunica, como una persona cuya voz resuena a través de una máscara. Será, para Levinas, el rostro o la presencia-ausencia de la alteridad absoluta e in-aferrable que en su mostrarse exige en imperativo, por lo que, a la vez, mantiene una distancia gracias a la cual constituye al yo como mismidad herida que responde: sujeto ético, no ontológico.

De ahí que para Levinas la relación no violenta con el otro sea el lenguaje originario, el lenguaje en el caso dativo ${ }^{12}$. Es decir, el cara-a-cara. Un cara-a-cara que en el caso de la crítica derrideana será precisamente el punto que, debido a la exigencia de inmediata presencia a sí del otro a través del rostro, impida a la ética levinasiana plantearse como una relación verdaderamente no violenta. Esta es la razón por la que la deconstrucción del sujeto soberano por parte de Derrida será continuada hasta la crítica misma de la noción de "humano" y de "persona". Y entiéndase bien, en el caso de Derrida no se criticará únicamente las construcciones "humanistas" -griegas, romanas o modernas- de lo "humano" y la "persona", sino las mismas condiciones de posibilidad y de sentido que puedan dar lugar a cualquier concepto y/o definición de "humano" y/o "persona" habida o por haber. No hay humanismo del otro en Derrida por la sencilla razón de que no hay nada "humano" o "no-humano" en Derrida13.

El cuestionamiento al humanismo que surge de las obras de Levinas y Derrida es radical, ya que asume sin ambages que es necesario superar la noción de persona tal y como la ha definido la filosofía. Para el lituano ello supondrá una rehabilitación del humanismo, de un humanismo de otro tipo: el humanismo del otro. Para el argelino, debido a su visión de lo humano mismo -siempre teniendo en cuenta que esta categoría únicamente puede atribuirse de un modo impropio al empleo que el pensamiento derrideano hace de ella, como suplemento14- la crítica del huma-

es una fenomenología de ausencias. Cfr. Guillot, D. E., "Introducción”, Levinas, E., Totalidad e infinito. Ensayo sobre la exterioridad, Salamanca, Sígueme, 1977, p. 21.

12 Cfr. Levinas, E., Totalidad e infinito. Ensayo sobre la exterioridad, Salamanca, Sígueme, 1977, p. 63. Esto significa que el lenguaje establece una relación irreductible a la relación sujeto-objeto y supone interlocutores. Y esos interlocutores a los que se dirige el lenguaje-contenido "n'appartient pas à la sphère inteligible à explorer", Levinas, E., Autrement qu'être. Au-délà de l'essence, La Haya, Nijhoff, 1978, p. 31.

13 El lugar donde Derrida desarrolló de manera más sistemática y explícita su crítica a la posibilidad misma de la noción de humano son los dos seminarios impartidos en la École des Hautes Études en Sciences Sociales durante los años 2001 y 2003, publicados posteriormente en Derrida, J., Séminaire La bête et le souverain I, Paris, Éditions Galilée, 2008 y Derrida, J., Séminaire La bête et le souverain II, Paris, Éditions Galilée, 2010.

${ }^{14}$ La noción de "suplemento", desarrollada en los inicios del pensamiento derrideano, es una de las constantes que atraviesa toda su obra hasta el punto de considerarse esencial a la deconstrucción de cualquier texto y/o discurso. Será la identificación de los "suplementos" constituidos por un discurso, de aquellos puntos que se identifican como "suplemento", la que dará lugar a la deconstrucción de un discurso. De forma resumida podemos afirmar que un suplemento es la relación de sustitución de una presencia supuestamente originaria cuya única razón de ser es intentar suplir una falta que se afirma 
nismo supondrá una primera identificación de los conceptos de "humano" y "persona" en tanto que suplementos técnicos, 15 conceptuales, jurídicos y lingüísticos mediante los que se suple la falta de una esencia o verdad última de nosotros mismos. Por lo tanto, en Derrida no habrá ninguna rehabilitación del humanismo porque, como ya hemos dicho, propiamente hablando no hay nada que rehabilitar ni del lado de lo "humano" ni del de la "persona".

\section{El sujeto vulnerable y pasivo: La ipseidad constituida por la alteridad}

Lo absolutamente Otro, es el Otro [...] Ni la posesión, ni la unidad del número, ni la unidad del concepto, me incorporan al Otro. 16

La crítica al humanismo toma una deriva propia en los años sesenta en torno al conocidísimo lema "el hombre ha muerto", o lo que es lo mismo, el sujeto soberano que se entiende a sí mismo como libre y autónomo, el sujeto epistemológico que se concibe a sí mismo como la fuente de la inteligibilidad del saber, es una mera ficción o construcción. Las posturas estructuralistas y post-estructuralistas que acuñan el lema, y de las que es coetáneo Levinas, marcan una dirección que el lituano comparte en parte, pero ante la cual reacciona. Eso es debido a que el balance levinasiano toma como punto de partida el comienzo de la filosofía más que la situación coetánea a él.

que no existe. En palabras de Derrida a propósito de Rousseau, la lógica del suplemento es explicada como sigue: "Rousseau dice A y luego interpreta, por razones que debemos determinar, A por B. A, que era ya una interpretación, es reinterpretada por B. Sin salir del texto de Rousseau y tras haber tomado nota de ello, podemos aislar a A de su interpretación por B y descubrirle sus posibilidades, recursos de sentido que pertenecen por cierto al texto de Rousseau pero no han sido producidos o explotados por él. Y a los cuales, por motivos también legibles, él ha preferido acortar, con un gesto ni consciente ni inconsciente", Derrida, J., De la gramatología, Buenos Aires, Siglo Veintiuno Editores, 2003, p. 85.

15 Una de las principales tesis configuradoras del presente artículo es la aproximación de la noción derrideana de "suplemento" a la de mediación técnico-artística. Una técnica que aquí entendemos como propia de una concepción de la política como praxis intersubjetiva, como hacer-se(r) del uno por el otro y viceversa, haya o no haya decisión de ese hacer-se(r). En última instancia, concebimos el lenguaje como la técnica propia con la que se realiza performativamente en la comunidad política el espaciamiento derrideano que inscribe el siempre à venir de la temporalidad. En esta noción de espaciamiento seguimos la concepción mantenida por Martin Hägglund y no la propia de Critchley o Caputo. Para una exposición de esta comprensión que excedería los objetivos del presente artículo remitimos a Hägglund, M., "The Radical Evil of Deconstruction. A Reply to John Caputo", en Journal for Cultural and Religious Theory, n. 11.2, pp. 126-150.

16 Levinas, E., Totalidad e infinito, p. 63. Es la filosofía la que se ocupa de esa desmesura: "La philosophie est cette mesure apportée à l'infini de l'être-pour-l'autre de la proximité", Levinas, E., Otherwise than Being or Beyond Essence, The Hague, 1981, p. 161. 
La obra de Levinas acentúa, desde el inicio, las notas discordantes y los elementos de separación respecto a la filosofía occidental, a ese pensar que va de Jonia a Jena, y lo hace porque concibe la metafísica como estando dirigida hacia "otra parte", hacia "lo otro", hacia un "fuera de sí". En este sentido, se apropia de la crítica heideggeriana a la metafísica como un saber que ha olvidado lo más importante. Pero se distancia del germano al indicar que la metafísica no se reduce a ontología -o que la ontología no es fundamental-y al sostener que lo que se ha olvidado es el otro, así como el valor de la vulnerabilidad: "El humanismo occidental no ha sabido nunca dudar de los triunfos, no ha sabido nunca comprender los fracasos, ni percibir una historia en la cual los vencidos y los perseguidos podrían aportar un sentido válido" 17 .

La acusación que realiza Levinas a ese modo de concebir la realidad propio de la metafísica es que es una filosofía de la identidad o de la ipseidad, que es alérgica a la alteridad 18 . Desde los filósofos griegos, la alteridad ha sido considerada en clave ontológica por lo que ha sido reducida a la diferencia, a ser otro ser o de otro modo, y no a ser de otro modo que ser ${ }^{19}$. Es decir, la filosofía ha comprendido la diferencia como un rasgo categorial y no como algo trascendental. Es un pensar que no ha captado que "la diferencia absoluta, inconcebible en términos de lógica formal, sólo se instaura por el lenguaje" 20 . Por ello la filosofía de la identidad se ha construido a partir de y sobre la incomprensión del otro, del totalmente otro, lo que ha dado lugar a una totalidad inmanente y excluyente que ha pasado al plano práctico, a la política. El pensar filosófico no es neutro, no se queda en un plano teórico, sino que se plasma en el modo en el que los seres humanos configuran su mundo y conviven ${ }^{21}$.

17 Levinas, E., Difficile liberté: essai sur le judaïsme, Paris, Albin Michel, 1976, p. 361.

18 Cfr. Levinas, E., Totalidad e infinito, p. 310. Al afrontar la filosofía de Heidegger como ontología fundamental, Levinas dirá que es una filosofía de la violencia y de la injusticia que no pone en cuestión al mismo. Cfr. Greisch, J., "Heidegger et Levinas interprètes de la facticité", en Positivité et transcendance: suivi de Lévinas et la phénoménologie, Paris, PUF, 2000, p. 200.

19 Levinas dedica su segunda gran obra a establecer el uso de los términos "Essence/essance" como "être", "Eidos, eidétique, eidétiquemente, nature, quiddité y fondamentale" como "essence" en sentido tradicional. Igualmente destaca la diferencia que hay entre "de otro modo que ser ("autrement qu'être) y ser de otro modo ("être autrement") e identifica el de otro modo que ser con la trascendencia. Cfr. Levinas, E., Autrement qu'être, pp. 3-4.

${ }^{20}$ Levinas, E., Totalidad e infinito, p. 208. Esto se cifra en la diferencia entre Decir y dicho. El Decir pre-originario (la responsabilidad) paga el precio de su manifestación en lo dicho, al que queda subordinado y en el que es disimulado. De ahí la exigencia del desdecirse y del pensamiento diacrónico. Cfr. Levinas, Autrement qu'être, pp. 6-8. Y de que ese desdecir se desdiga de nuevo sin alcanzar ninguna fórmula definitiva. Cfr. Levinas, E., De Dios que viene a la idea, Madrid, Caparrós, 2001, p. 125.

${ }^{21}$ En un escrito de 1934 Levinas pone de relieve la concepción teórica sobre la que se apoya el nazismo. Cfr. Levinas, E., "Quelques réflexions sur la philosophie de l'hitlérisme", Les imprévus de l'histoire, Paris, Fata Morgana, 1994, pp. 27-41. 
Para Levinas eso supone que, si bien es cierto que la filosofía ha generado una comprensión de la política como democracia, a su vez ha provocado violencia y guerras, lo que muestra que su mayor debilidad reside en su deficiente comprensión del sentido de lo humano que convierte al otro en exterminable y enfrenta al filósofo con el problema de la incompatibilidad de la moral y la política o a la pregunta $i$ es la moral una farsa?, pues la política, "el arte de prever y ganar por todos los medios la guerra, se opone a la moral. La guerra se presenta como la experiencia pura del ser puro, en el momento mismo de su fulgor en el que se queman los decorados de la ilusión"22.

El humanismo europeo es para el filósofo lituano un humanismo insuficiente, que ha culminado - o al menos no ha evitado la culminación- en la muerte del hombre en su forma más inhumana: el genocidio. Y esto no es algo circunstancial, pues está unido a la noción de ser humano que está ligada a la filosofía de la identidad. El lituano establece, por tanto, una lectura de la Shoah que inculpa a toda la filosofía, a todo el pensar ontológico de la mismidad en el que la alteridad primero no ha encontrado el lugar que le corresponde y después ha sido excluida, por asimilación o por exterminación ${ }^{23}$. Ello significa que no es solo la filosofía moderna o la modernidad la que conduce hacia la exclusión-genocidio, sino que esa es una posibilidad inherente a todo el pensar político que nace en Grecia: "el sentido de lo humano no está sólo mal protegido sino tal vez mal formulado en el humanismo greco-romano" 24.

En este punto es importante no perder de vista que Levinas, por una parte, considera muy valiosa la concepción griega de la política y que, a pesar de su crítica a la "sabiduría de las naciones" 25 , sostiene que la dimensión institucional es imprescindible para que, en la práctica, el ser humano sea respetado 26 . Sin embargo, por otra parte, incide en que sin una afirmación primera, an-árquica de la alteridad radical no es posible la política: "lo que queda fuera de consideración, en esta eventualidad es que es necesaria una orientación que le lleva a preferir la palabra a la guerra"27. La ética, el reconocimiento del otro es an-árquica, no es el resultado de un diálogo o de un acuerdo político.

\footnotetext{
22 Levinas, E., Totalidad e infinito, p. 47. Es más, la paz que se logra por medio de la política es solo mediación y comercio, pues sigue estando en el nivel del ser y del interés. Cfr. Levinas, Autrement qu'être, p. 5.

${ }^{23}$ Lévinas desarrolla la acusación a la filosofía que reduce todo a la mismidad y se convierte en narcisista, ególatra y excluyente-dominadora en "La philosophie et l'idée de l'Infini", en Revue de Métaphysique et de Morale, 1957, pp. 241-261.

24 Levinas, E., Difficile liberté, p. 361.

25 Levinas, E., De l'évasion, Montpellier, Fata Morgana, 1982, p. 99. Levinas considera que la lógica imperialista es inherente al poder político. Cfr. Levinas, E., Nouvelles lectures talmudiques, Paris, Minuit, 1968, p. 71.

26 Cfr. Fornet, R.; Gómez, A., Filosofia, Justicia y Amor. Entrevista con Emmanuel Levinas, en Concordia, 3/1983, p. 63.

27 Levinas, E., L'Humanisme de l'autre homme, Paris, Fata Morgana, 1972, p. 44.
} 
Ahí es donde se encuentra el eje del pensamiento de Levinas, que tratará de poner de relieve que la experiencia de la alteridad no está unida a una conciencia representativa ni temática. Esa experiencia primaria del otro es la que ha de tomarse como punto de inicio para alcanzar una nueva definición del ser humano, y a partir de ahí de la política. La filosofía levinasiana es, en este sentido, una comprensión del humanismo que se opone a la antropología occidental: el principio no es el poder, no es el sujeto soberano. El principio es la vulnerabilidad, el no poder poder, el ser sujeto-a o rehén del otro: "La expresión que el rostro introduce en el mundo no desafía la debilidad de mis poderes, sino mi poder de poder. El rostro [...] perfora la forma que, sin embargo, la delimita. Lo que quiere decir concretamente: el rostro me habla y por ello me invita a una relación sin paralelo con un poder que se ejerce, ya sea gozo o conocimiento"28. Es decir, Levinas comparte, como ya se ha señalado, la idea antihumanista de que el sujeto soberano es un constructo que ha sido elaborado por el humanismo occidental.

A partir de esta crítica, Levinas planteará su humanismo, cuyo significado se ve mejor si se tiene en cuenta que el lituano toma como referencia a la hora de entender el humanismo occidental a Kant. Para el regiomontano, el hombre es un ser personal, que es un fin en sí mismo y nunca ha de ser tratado como un medio, lo que Levinas acepta. El problema, y punto de ruptura, reside en la definición del ser humano por su libertad entendida como espontaneidad y autonomía 29 . Desde este punto de vista, el hombre es un agente que realiza acciones libres de las que es responsable y es un ser digno en la medida en la que es dueño de sus acciones y capaz de responder de ellas ${ }^{30}$. Si esto es así, si la persona está vinculada a la autonomía y la soberanía, para Levinas se hace necesario abandonar esta noción: "la grandeza del antihumanismo moderno -verdadero más allá de las razones que otorgue- consiste en dar un lugar claro a la subjetividad de rehén eliminado la noción de persona"31. La imagen del ser humano como un ser autónomo, que es dueño de sus obras

${ }^{28}$ Levinas, E., Totalidad e infinito, p. 211. A pesar de ello, el yo todavía "puede matar [...] El homicidio ejerce un poder sobre aquello que se escapa al poder [...] El otro es el único ser al que yo puedo querer matar", Levinas, E., Totalidad e infinito, pp. 211-212.

29 Para conocer mejor la relación de Levinas y Kant en torno al humanismo, consúltese Renaut, A., "Levinas et Kant", en Positivité et trascendance, pp. 89-104. Este autor destaca que Levinas ha interpretado mal la tradición de la filosofía trascendental que va de Kant a Fichte, pues "dans l'idée d'autonomie l'ouverture à l'autre se trouve déjè comprise", p. 100. Para conocer en profundidad la relación de Kant y Levinas acerca de la ética, consúltese Chalier, C., Por una moral más allá del saber, Kant y Levinas, Madrid, Caparrós editores, 2002.

30 Cfr. Levinas, E., Liberté et commandement, Paris, Fata Morgana, 1994, pp. 32-33.

31 Levinas, E., Dios, la muerte y el tiempo, Madrid, Cátedra, 1994, p. 218. La progresión hasta la noción de rehén es clara: "La signification -l'un pour l'autre- la relation avec l'altérité -a été analysée dans le présent ouvrage comme proximité, la proximité comme responsabilité pour autrui, et la responsabilité pour autrui- comme substitution: dans sa subjectivité, dans son part même de substance separée, le sujet s'est montré expiation-pour-autrui, condition ou incondition d'otage", Levinas, Autrement qu'être, p. 232. 
y responsable de sus actos pretendía mostrar su grandeza, pero lo que ha logrado es apresar al ser humano en su identidad y crear una imagen irreal, una ficción.

Frente a esta concepción del ser humano, Levinas incide en la apertura a la trascendencia, en la aparición del noúmeno que rasga la totalidad desde la misma exterioridad que, ahora, permaneciendo alter y exterior, constituye a la ipseidad ${ }^{32}$. Y aquí reside la diferencia fundamental con los autores antihumanistas. Levinas rehabilita el humanismo incidiendo en la apertura y mostrando que la trascendencia es posible porque esta constitución de la identidad por medio de la alteridad no es ontológica, sino ética. Para Levinas la llegada de lo que viene de fuera, de lo otro, que es el otro, se hace patente en el rostro y se produce, como ya se ha señalado, de una forma an-árquica, como puro don gratuito, que enseña al hombre quién es realmente, ya que lo eleva a la responsabilidad: "El término Yo significa heme aqui, respondiendo de todo y de todos. La responsabilidad para con los otros no ha sido un retorno sobre sí mismo, sino una crispación exasperada, que los límites de la identidad no pueden retener. La recurrencia se convierte en identidad al hacer estallar los límites de la identidad, el principio del ser en mí, el intolerable reposo en sí de la definición. [...] La responsabilidad dentro de la obsesión es una responsabilidad del yo respecto a lo que ese yo jamás ha querido, es decir, respecto a los otros"33.

La responsabilidad surge, pues, ante esa manifestación del otro que tiene significado en sí mismo, que es visitación que habla, que apela, y que es humano en sí mismo ${ }^{34}$. Y eso significa que, al hablar a un ser concreto, reclama la palabra singular que individualiza: "La idea del ser que desborda la historia hace posible entes a la vez comprometidos en el ser y personales, convocados a responder por su proceso $\mathrm{y}$, en consecuencia, ya adultos, pero, por esto mismo, entes que pueden hablar, en lugar de prestar sus labios a una palabra anónima de la historia"35. El rostro que individualiza es la proximidad sin simultaneidad de dos seres que entran en contacto manteniendo la separación y la alteridad porque el otro se presenta como humano "antes" del tiempo de la conciencia y de la libertad.

\footnotetext{
32 Levinas usa diferentes términos para referirse a esa alteridad que no es englobable en la totalidad pero es tan original como ella, e incide en que esta experiencia no se describe solo de manera negativa, sino que es algo que se refleja en el interior de la totalidad, la historia y la experiencia interpelando y convocando a los seres en su responsabilidad. Cfr. Levinas, E., Totalidad e infinito, p. 49.

33 E. Levinas, Autrement qu'être, pp. 145-146. La idea clásica de responsabilidad, que implica las nociones de razón y de imputación, es modificada por Levinas para indicar la exigencia de respuesta ante el otro y la asimetría de dicha respuesta. Cfr. Waldenfels, B., "La responsabilité", Positivité et trascendance, pp. 261-262.

$34 \mathrm{El}$ rostro revela porque fenomenaliza lo que nunca se ve, pero como solo se muestra como rostro sin individualizar, no es una aparición como persona. De ahí que para Marion sea necesario el amor. Cfr. Marion, J. L., "D’autrui à l'individu”, Positivité et trascendance, pp. 294-296.

35 Levinas, E., Totalidad e infinito, p. 49.
} 
En este sentido, lo que Levinas destaca es que lo propio del ser humano es la responsabilidad, lo que permite recuperar la fraternidad 36 . El hombre no sólo ha de responder de sí mismo, ha de responder del otro, del lejano que, siendo otro, es hermano, ya que ser hermano es ser responsable, tener que responder del y por el otro. Ahora bien, esta fraternidad no supone, de ninguna forma, la existencia de un género ni de nada común entre los seres humanos, ya que la alteridad del otro es siempre radical, absoluta e irreductible: "El cara-a-cara, a la vez, anuncia una sociedad y permite mantener un yo separado" 37 . Este humanismo que cuestiona la prioridad de lo mismo busca establecer la apertura y recepción del otro en el mismo como un elemento constitutivo del propio sujeto: "Yo es otro"38. La subjetividad del sujeto es su propia apertura a la alteridad 39 . Y para que esto se cumpla adecuadamente, es necesario que el otro concierna al yo, permaneciendo exterior, y que le haga salir de sí mismo ${ }^{40}$. Lo que impide la totalidad no es, pues, la insuficiencia del yo, sino la infinitud del otro que se hace patente en el lenguaje: "El discurso, por el hecho mismo de mantener la distancia entre yo y el Otro, la separación radical que impide la reconstitución de la totalidad, y a la que aspira en la trascendencia, no puede renunciar al egoísmo de su existencia, pero por el hecho mismo de encontrarse en un discurso, consiste en reconocer al Otro un derecho sobre ese egoísmo y así, en justificarse" 41 .

El yo ha de justificarse porque el otro impone un mandato imperativo al que hay que responder ${ }^{42}$. Por tanto, la apertura propia del sujeto como respuesta a la apela-

36 "Cette façon de répondre sans engagement préalable - responsabilité pour autrui - est la fraternité humaine elle-même, antérieure à la liberté”, Levinas, Autrement qu'être, pp. 148-149.

37 Levinas, E., Totalidad e infinito, p. 91. Levinas desarrolla estas ideas en "Le Moi et la Totalité", en Revue de Métaphysique et de Morale, 1954, pp. 353-373.

38 E. Levinas, L'humanisme de l'autre homme, p. 88.

39 Cfr. Levinas, E., Totalidad e infinito, p. 52. Esta recepción del otro en el mismo es la hospitalidad. Cfr. Levinas, E., Totalidad e infinito, p. 304.

40 "La estructura formal que encuadra esta experiencia de la alteridad es la idea de lo infinito cuyo contenido consiste en sobrepasar permanentemente todo contenido y por la cual se contiene más de lo que se puede contener", Guillot, D. E., "Introducción", p. 25. Por otra parte, esta presencia de la alteridad en al mismidad que constituye la subjetividad es la proximidad. Cfr. Lévinas, E, "La proximité", en Archives de Philosophie, 34, 1971, pp. 373-391. Ahora bien, es importante no perder de vista que proximidad no es lo mismo que parecido ni algo en común. Cfr. Levinas, E., "Transcendance et hauteur”, en Bulletin de la Société Française de Philosophie, 1962, pp. 107-109.

${ }^{41}$ Levinas, E., Totalidad e infinito, pp. 63-64.

42 Cfr. Hayat, P., "La philosophie entre totalité et transcendance", en Altérité et transcendance, Paris, Fata Morgana, 1995, pp. 12-13. Es en este punto donde nuestra propuesta presenta una clara ruptura con la lectura esgrimida por Simon Critchley en su The Ethics of Deconstruction: Derrida and Levinas, al concebir el autor inglés, a nuestro modo de ver, un acercamiento excesivo de la ética derrideana a la línea hermenéutica más kantiana de las posibles lecturas de Levinas. En nuestra interpretación de la obra de Derrida, al igual que en la de Hägglund, será la mediación temporal, el dar el tiempo del otro a uno mismo como apertura pre-ontológica a la otredad lo que primará en la relación con 
ción del otro es, a su vez, su vulnerabilidad, su pasividad radical, que es definida por Levinas con los términos de sustitución, responsabilidad y expiación. El sujeto como sujeto-a es un ser marcado por la pasividad y el no poder poder, por la apertura a una trascendencia o exterioridad, que ni en su modo de presentarse ni en su modo de constituir a la ipseidad es gnoseológicamente apresable ni ontológicamente fundamento o principio. Es la experiencia anterior al conocimiento y a la inteligibilidad que tiene lugar en la oscuridad de la noche y no es alcanzable por la luz, lo que resitúa a la fenomenología que, como comprensión por la iluminación, "no constituye el acontecimiento último del ser"43.

Así pues, a la hora de redefinir el humanismo, a Levinas lo que más le interesa es destacar que la ruptura de la totalidad o de la ipseidad se realiza como un éxodo o salida de sí en respuesta a una llamada exterior. De ahí que señale que esta salida hacia el otro es el Deseo o la sociabilidad y que este no es fruto de una necesidad o insatisfacción de un ser consigo mismo. La relación con el otro, que cuestiona al yo y le enfrenta consigo mismo, se convierte en constitutiva de la identidad de un ser que está volcado hacia los demás y no puede ser sí mismo sin esa apertura porque la salida es tan inherente al yo como el conatus essendi ${ }^{44}$. Pero no por ello esa trascendencia se transforma en sustrato o sustancia del sujeto, sino que continúa siendo la ruptura de su ipseidad autosuficiente.

La crítica levinasiana al humanismo occidental culmina en el humanismo del otro, en ese pensar que señala que la recepción de la trascendencia es una relación con el otro que es asimétrica porque exige la responsabilidad del yo frente al otro, pero no la del otro hacia el yo. La llegada del otro desgarra al yo y lo despierta ${ }^{45}$,

esta última, y no un irracional mandato de responsabilidad absoluta por el otro en tanto que nuevo imperativo categórico de corte levinasiano. Para una exposición de las lecturas levinasiano kantianas de la obra de Derrida remitimos a Critchley, S., The Ethics of Deconstruction: Derrida and Levinas, Edinburgh, Edinburgh University Press, 1992.

43 Levinas, E., Totalidad e infinito, p. 54. Aunque aclara Levinas que "la presentación y el desarrollo de las nociones empleadas lo deben todo al método fenomenológico [...] lo que cuenta es la idea del desbordamiento del pensamiento objetivante por una experiencia olvidada de la cual vive", Levinas, E., Totalidad e infinito, p. 54. Levinas critica en sus primeros escritos a Husserl y le acusa de haber caído en el intelectualismo y de no haber mantenido la promesa presente en la noción de intencionalidad pre-predicativa. Cfr. Levinas, E., Positivité et trascendance, pp. 35-36. Sin embargo, posteriormente, considera que Husserl ha vislumbrado la alteridad y es capaz de abrirse a la ética. Cfr. Levinas, E., Totalidad e infinito, p. 144. Para ampliar esta relación, consúltese Colette, J., "Lévinas et la phénoménologie husserlienne", en Les Cahiers de la nuit surveillée, Lagrasse, Verdier, 1984, pp. 19-36. En el caso de Heidegger, la relación es más bien inversa: comienza reconociendo su filosofía y pensando desde ella, pero luego le acusa de haber olvidado a los seres y al otro para caer en una ontología fundamental. Cfr. Levinas, E., Totalidad e infinito, p. 111. Para ampliar esta relación, consúltese Petitdemange, G., "L'un ou l'autre. La querelle de l'ontologie: Heidegger-Lévinas", en Les Cahiers de la nuit surveillée, pp. 37-49.

44 Cfr. Levinas, E., L'humanisme de l'autre homme, p. 97

45 La filosofía es despertar y ese despertar hace posible la ética vista como otra racionalidad. Cfr. Levinas, E., Positivité et transcendance, pp. 16-31. 
elevándolo a la toma de conciencia de su responsabilidad, que no es intercambio de favores: es justicia46. El yo que recibe al otro comprende que ser yo es responder al otro y del otro y que el otro es otro sin la intervención del yo. Este es el sentido de la ética, de ese modo de relacionarse con el otro que respetará su alteridad sin buscar apropiársela o reducirla, lo que permite "hacer de nuevo posible la expresión en la que, en la no-reciprocidad, la persona se presenta como única. La justicia es el derecho a la palabra" 47 .

El humanismo que reconoce el derecho a la palabra, la justicia, como aspecto primario en la constitución de la identidad del yo pone de relieve que el ser humano no es ese famoso sujeto libre, autónomo, soberano y detentor de poder o poderes. El hallazgo de la falacia de esa imagen mítica es el gran logro del antihumanismo. Ahora bien, ante el certificado de defunción emitido por el antihumanismo, Levinas considera que no se puede volver a una filosofía de la sustancia, pero estima necesario salir de este clima: "No aceptar que el ser sea para mí, no es rechazar que él es en vista del hombre, no es dejar el humanismo [...] es únicamente rechazar que la humanidad del hombre resida en su posición de Yo. El hombre, por excelencia -la fuente de la humanidad- es quizás el Otro"48. Por ello para el filósofo lituano es urgente afirmar que la libertad es justa si reconoce su origen heterónomo -el mandato- y que no es un valor absoluto, sino que se justifica por algo que es externo a sí misma: "La libertad debe justificarse. Reducida a sí misma, se lleva a cabo, no en la soberanía, sino en la arbitrariedad. [...] La libertad no se justifica por la libertad" 49 .

Es decir, el humanismo del otro no es un antihumanismo, aunque parte de una constatación común, sino una comprensión nueva del ser humano que muestra lo que ha sido olvidado y excluido por la filosofía de la ipseidad, que ahora ha sido des-en-mascarada y puesta al descubierto. Y, por ello, des-personalizada, devolviendo al ser humano su vulnerabilidad, su ser más que sustancia, también más que su ser sustancia individual de naturaleza racional ${ }^{50}$. El sujeto desenmascarado se muestra, por tanto como sujeto para otro, abierto y responsable: "Ser yo es siempre tener una responsabilidad de más" 51 . Una vez que la máscara ha caído, el sujeto herido es capaz de poner de relieve el valor del fracaso y de todo lo que ha sido excluido por el humanismo clásico.

Las críticas a Levinas por lo desmesurado de su propuesta no tardaron en llegar: ¿No es necesaria una mediación, un espacio entre yo y otro para que haya ética?

\footnotetext{
46 Levinas, E., Entre nosotros, p. 193. La gratuidad está unida a la diacronía, la asimetría y la falta de reciprocidad. Cfr. Levinas, E., "Entretien avec Emmanuel Lévinas", p. 310.

47 Levinas, E., Totalidad e infinito, p. 302.

48 Levinas, E., Liberté et commandement, p. 59.

49 Levinas, E., Totalidad e infinito, p. 307.

50 Cfr. Rolland, J., "Subjectivité et an-archie", en Les Cahiers de la nuit surveillée, pp. 177-181.

51 Levinas, E., Entre nosotros. Ensayos para pensar en otro, Valencia, Pre-Textos, 1993p. 78.
} 
¿El otro no es más terrorista y totalitario que la totalidad instituida por el mismo?52. Ante tales preguntas, Levinas sostiene que "el 'descubrimiento' del otro -no precisamente como dado, sino como rostro- subvierte el acercamiento trascendental al yo pero conserva el primado egológico de ese yo que permanece único y elegido en su responsabilidad irrecusable" 53 . El yo oreja atenta al otro se desgarra por él y en esa hemorragia se constituye como subjetividad, pero no como persona entendida como actor que se esconde tras la máscara. Esa subjetividad des-en-mascarada se presenta como una voz que responde y en su respuesta al otro se convierte en sí misma.

\section{Hors de l'humain: Violencia y bestialidad en la constitución de la persona}

El segundo discurso [Marx] es político: es breve y directo, más que breve y más que directo, ya que cortocircuita todo discurso. No acarrea ya un sentido, sino una llamada, una violencia, una decisión de ruptura. No dice nada, propiamente dicho; es la urgencia de lo que anuncia, vinculada a una exigencia impaciente y siempre excesiva, puesto que el exceso es su única medida: así, al llamar a la lucha e incluso (cosa que nos apresuramos en olvidar) al postular el terror revolucionario, al recomendar la revolución permanente y al designar, siempre, la revolución no como una necesidad a plazo sino como una inminencia, pues es carácter propio de la revolución el no ofrecer demora, sí abre y atraviesa el tiempo, haciendo que se la viva como exigencia siempre presente. 54

Frente a las primeras consideraciones de la influencia levinasiana en la obra de Derrida que, al modo de la realizada por Simon Critchley en The Ethics of Deconstruction, terminaban por concluir una quasi-imposibilidad de la existencia de una política propiamente derrideana debido a una excesiva homología de la ética derrideana con la levinasiana (basadas ambas en lo absoluto e indeconstruible del mandato de responsabilidad por el otro), la propuesta aquí presentada intentará por el contrario exacerbar hasta el máximo las diferencias existentes entre la ética levinasiana y la ética derrideana con el propósito explícito de intentar abrir un nuevo frente de deconstrucción de lo político a partir de la crítica al humanismo y la noción misma de lo humano.

\footnotetext{
52 Cfr. Haar, M., “L'Obsession de l'autre. L'éthique comme traumatisme”, pp. 451-452.

53 Lévinas, E., "Entretien avec Emmanuel Lévinas", en Revue de Métaphysique et de Moral, 1985, p. 309.

54 Palabras de Blanchot citas por Derrida en Derrida, J., Espectros de Marx. El estado de la deuda, el trabajo del duelo, y la nueva internacional, Barcelona, Editorial Trotta, 2003, p. 46.
} 
Para ello, la lectura que hacemos de la relación Levinas-Derrida hará hincapié, al igual que las lecturas de Hägglund, en la estructura temporal del à venir como estructura dentro de la cual debe ser insertada la ética derrideana de la responsabilidad por el otro, sin llegar a entender dicha responsabilidad como un mandato absolutamente trascendente a esta estructura temporal, a la que el propio Derrida se refiere como la posibilidad misma de "dar el tiempo"55. Será este cambio de enfoque en la lectura de la ética derrideana el que nos permitirá esgrimir una lectura de lo político como el conjunto de praxis intersubjetivas orientadas a funcionar como mediación, técnica y suplemento de la ausencia originaria propia de la estructura del à venir. Una mediación-suplemento en cuya economía de la violencia se decidirá la auto-medición del hombre por el hombre a través del concepto de lo humano.

Desde este punto de vista, en nuestra interpretación de la obra derrideana, la deconstrucción sin límites que este último realiza del discurso humanista del sujeto soberano en modo alguno llega al intento de constitución de una subjetividad vulnerable que prescinda de toda consideración de lo humano como técnica de medida y exclusión. Para Derrida, toda relación con el otro, ya sea desde una subjetividad previamente constituida como soberana o desde una subjetividad siempre constituyente desde la presencia-ausencia del otro infinito, supone mediaciones técnicotemporales que de forma irremediable se configuran como suplementos de un movimiento previo que únicamente podemos identificar como "falta" o "ausencia" radical. En otras palabras, no será posible constituir una subjetividad vulnerable por completo ajena a la mediación técnica en que consiste la persona y lo humano.

Concretamente, para Derrida, esta supuesta vulnerabilidad y pasividad en la constitución de la ipseidad del sujeto levinasiano desde la trascendencia de una exterioridad del otro que permanece irreductiblemente exterior a sí mismo supone la misma lógica básica de la auto-posición soberana, propia de la ontología y la fenomenología occidentales, que Levinas pretendía eludir. Para el argelino, incluso teniendo en cuenta el modo ético-no-ontológico de la relación con el otro defendido por Levinas, es necesario suprimir la temporalidad propia de dicha relación ética si queremos poder aspirar a una relación no violenta con el otro. De este modo, para Derrida, la propuesta levianasiana seguiría siendo deudora de una temporalidad obsesionada por la presencia a sí de toda experiencia que torna superfluo cualquier intento de romper la ipseidad del sujeto moderno.

Esta crítica temporal de Derrida a Levinas encarna todo su potencial cuando es leída de forma simultánea con la realizada a la fenomenología husserliana pocos

55 Desde el punto de vista de Häggglund, "the unconditional does not belong to a different 'order' than the here and now. The unconditional is the spacing of time, that is the structure of the here and now, the structure of what happens, of the event. That I insist on this point does not mean that I think deconstruction is a 'pure description' (a phrase I have never used) or a value-free enterprise that does not engage in performative acts of commitment", Hägglund, M., "The Radical Evil of Deconstruction”, p. 137. (El subrayado es nuestro). 
años después 56 . Es a través de una lectura transversal de ambos autores como Derrida plantea claramente cómo el punto suplementario que se produce tanto en la constitución de la subjetividad soberana como de la subjetividad vulnerable es una cuestión de tiempo. En última instancia, aduce Derrida que puesto que la otredad del otro consiste en ser origen de un mundo fuera del mío, pero que a la vez coconstituye el mío, la otredad de mi mundo es previa a mi mundo, marcando de esta forma una ausencia originaria en el origen mismo de la presencia a mí de mi propio mundo: "El acceso al alter ego no se da en ninguna intuición originaria, sólo en una analogía, en lo que él llama una 'apresentación' analógica. Nunca se está del lado del otro, de su aquí-ahora originario, nunca se está en su cabeza, si se quiere. Brecha esencial en la fenomenología"57.

Así pues, si, como afirma Derrida, para Levinas "el yo no puede engendrar en sí la alteridad sin el encuentro del otro" 58 , entonces la presencia del otro en el yo no puede sino tener la estructura de una ausencia no directamente presente. Ahora bien, la lógica del suplemento derrideana afirma que dicha ausencia no es ausencia de algo que una vez fue una presencia, sino que la ausencia del otro está constitutiva y únicamente presente como la posibilidad misma del otro en mí; esto es, como una falta esencial que constituye la abertura al mundo (en) que (me) constituyo (como humano y como persona) a través de suplementos. Mientras que para Levinas la llegada de lo otro se hace patente en el rostro que nos llega como puro don gratuito, para Derrida, en cambio, la única llegada que nos puede llegar como puro don gratuito en modo alguno será el rostro, sino única y exclusivamente el tiempo. La llegada completamente gratuita del otro como don puro exige una ruptura completa de la noción cronológica de presente: "El presente" del don ya no se puede pensar como un ahora, a saber, como un presente encadenado a la síntesis temporal"59. Si eso sucediera, lo dado no estaría dado de verdad, no constituiría un don realmente

\footnotetext{
56 Si bien es cierto que existe una primera crítica derrideana de la obra de Husserl realizada a propósito de la introducción a la traducción francesa de El origen de la geometría (1959) y que es anterior a la primera crítica de la obra levinasiana (1964), por simplicidad conceptual nos referiremos exclusivamente a la posterior crítica a Husserl realizada con la publicación en 1967 de La voz y el fenómeno. 57 Derrida, J., Papel Máquina, p. 329.

58 Derrida, J., "Violencia y metafísica. Ensayo sobre el pensamiento de Emmanuel Levinas", en Derrida, J., La escritura y la diferencia, Barcelona, Editorial Anthropos, 1989, p. 128. Desde la óptica levinasiana, podría responderse a esta acusación que no es el yo el que genera la alteridad en sí mismo en el encuentro del otro, sino que la alteridad del otro es la apertura del tiempo y de lo otro del tiempo presente, o porvenir: "La invasión del porvenir por parte del presente no acontece al sujeto en solitario, sino que es la relación intersubjetiva. La condición del tiempo es la relación entre seres humanos, la historia. [...] [el futuro] es completamente diferente y nuevo. Sólo de este modo podemos comprender la realidad misma del tiempo, la imposibilidad absoluta de encontrar en el presente algo equivalente al porvenir, la carencia de toda aprehensión del porvenir", Levinas, E., Le temps et l'autre, pp. 121-123.

59 Derrida, J., Dar el tiempo I. La moneda falsa, Barcelona, Paidós Ibérica, 1995, p. 19.
} 
puro, realmente gratuito, sino que sería el efecto mecánico de un cálculo contable con vistas a una futura restitución y/o beneficio: "Si hay don, lo dado del don no debe volver al donante. No debe circular, no debe intercambiarse, en cualquier caso no debe agotarse, como don, en el proceso del intercambio [...] el don debe seguir siendo an-económico"60. Es únicamente a condición de esa fractura en la linealidad circular del tiempo como podría haber don.

Yendo más allá de la necesidad de esta fractura del tiempo cronológico para que pueda haber don, la crítica radical derrideana al humanismo soberano y al humanismo del otro exige que para que esta venida del otro como don puro pueda darse, esta no puede presentarse bajo la fenomenología del rostro, pues una verdadera ética absoluta del don exige el no-re-conocimiento ${ }^{61}$. La deconstrucción derrideana del humanismo lleva entonces a la conclusión de que la única forma en que el otro puede llegar a nosotros como don puro previo a la configuración de la subjetividad propia es en la forma del tiempo. El otro debe ser siempre à venir, nunca rostro. Ni presente ni presente-ausente. Nuestra vulnerabilidad no es una responsabilidad por el otro, es la mediación del tiempo que nos da el otro y que en su mismo darse nos configura como faltas, como seres abiertos que necesitan de suplementos para autoconstituirse frente al otro como dador de tiempo ${ }^{62}$. Lo que el otro nos da es nuestra misma necesidad de auto-constituirnos como personas mediante suplementos protéticos. Su "acción" sobre nosotros es una no-presencia radical, es únicamente apertura. Responsabilidad por la apertura. No por el otro como persona constituida o humano imperativo.

Una vez expuestos los posteriores desarrollos de la crítica al humanismo del otro, la sentencia final sobre la propuesta levinasiana realizada en 1964 por un joven Derrida resulta sorprendentemente nítida: "Si el presente viviente, forma absoluta de la abertura del tiempo a lo otro en sí, es la forma absoluta de la vida egológica, y si la egoidad es la forma absoluta de la experiencia, entonces el presente, la presencia del presente y el presente de la presencia son originariamente y para siempre

60 Derrida, J., Dar el tiempo I, p. 17.

${ }^{61}$ El motivo de tal no reconocimiento es claro: "Si el don se le aparece como tal, si el presente le resulta presente como presente, este simple reconocimiento basta para anular el don. ¿Por qué? Porque este devuelve, en el lugar, digamos, de la cosa misma, un equivalente simbólico", Derrida, J., Dar el tiempo I, p. 22.

62 Esta es la razón por la que para Derrida la relación concreta con los otros, la amistad, ya no podrá darse bajo la forma de la com-unidad de semejantes, de la fraternidad (precedente indispensable y directo del concepto de "humanidad" propio del humanismo). Por el contrario, para Derrida, la amistad "pasa por el reconocimiento de la extrañeza común que no nos permite hablar de nuestros amigos, sino tan sólo hablarles", Derrida, J., Políticas de la amistad, p. 325. De este modo, desde una lectura en relación directa con el concepto de amistad esgrimido por Nietzsche y Blanchot, Derrida culminará afirmando que en la imposible (no) relación con el otro como dar tiempo, la amistad únicamente puede configurarse como la nunca realizada "llamada a franquear la distancia", Derrida, J., Políticas de la amistad, p. 328. 
violencia [...] La metafísica de Levinas presupone en un sentido la fenomenología trascendental que pretende poner en cuestión. Y sin embargo no nos parece menos radical la legitimidad de esa puesta en cuestión"63. Para Derrida, el-otro-frente-a-mí de la rostridad levinasiana no respeta suficientemente la otredad temporal del otro en la constitución de la apertura del yo. No toma suficiente distancia. No subraya suficientemente la diferencia pre-originaria. En la lectura derrideana no existe ningún heme aquí in-mediato de la presencia a mí del otro. Ni siquiera como ausencia. El otro no es una ausencia. El otro es dación de tiempo. La inmediación del otro levinasiano, la inmediatez de su rostro-mandato, es sustituida en Derrida por el "espaciamiento" o Khorà propia de la mediación técnica en la que consiste lo propio de la apertura del sujeto como imposibilidad de su auto-posición. Una mediación técnica que entendemos en el sentido con el que Hägglund se refiere a los permormative acts of commitment 64 .

La apertura al otro no es ética, es técnica. Lingüística, conceptual, económica, jurídica y temporalmente técnica. Multiplicidad política. Es la estructura lingüística del à venir propia de todos los sistemas abiertos, de todas las aperturas propias de la técnica en tanto que mediación del hombre con el mundo la que nos permite en última instancia la influencia del otro en la constitución de uno mismo y no un simple mandato incondicional de respuesta a modo de imperativo categórico. $\mathrm{Si}$ bien puede que haya un punto de locura en toda decisión, no la hay en la estructura del à venir. Reducir la co-constitución de uno mismo desde y por el otro a la de simple mandato incondicional al modo de las lecturas más kantianas de la ética levinasiana, antes que una verdadera escucha y co-constitución del otro-uno y el unootro mediante la dación del tiempo, es el principio mismo de la imposibilidad de la constitución de una política en el modo que aquí la entendemos. Pues es la misma posibilidad de constitución política la que excluye la in-mediación de cualquier tipo. El mandato no es absoluto, pues no hay mandato alguno. Únicamente apertura y co-constitución intersubjetiva pre-ontológica.

Del mismo modo que todo en la constitución siempre fracasada del sujeto y del yo es una mediación sin posibilidad de llegar a un núcleo originario de inmediatez ni en su forma originaria ni en su autoposición desde una previa mediación de lo otro, para Derrida tampoco es posible llegar a una concreción de la presencia o ausencia del otro como rostro ni siquiera como infinito. Al tiempo no cronológico no se lo concibe ni como presencia presente ni como ausencia pasada o futura, pues la dación del tiempo por el otro no es cronológica, tampoco kairótica como parece exigir el humanismo levinasiano, sino aiónica 65 : Homo-prótesis y cyborg transcendental.

63 Derrida, J., "Violencia y metafísica", p. 173.

64 Hägglund, M., "The Radical Evil of Deconstruction”, p. 137.

$65 \mathrm{Si}$ bien Derrida no emplea nunca el concepto de Aion en sus reflexiones sobre la temporalidad, un análisis exhaustivo del mismo puede revelar muchas coincidencias con la temporalidad no cronológi- 
Es, pues, este primado de la temporalidad aiónica sobre la dualidad presenciaausencia en la ruptura de la ipseidad del sujeto la que lleva directamente a la hipóstasis de la otredad como "acontecimiento (événement) à venir". O lo que es lo mismo, la otredad, el otro derrideano, en última instancia, se define primariamente mediante una relación temporal más allá de la simultaneidad temporal de la presencia, propia de la ipseidad del sujeto. El otro, sin ser tiempo, es lo que abre al mismo las constituciones pre-subjetivas de forma previa a la constitución del yo. Frente a esta apertura al tiempo mismo otorgada por el otro, las filosofias de la presencia pura, de la inmediación temporal, de la co-presencia noética en la que Husserl basaba su fenomenología, permanecerían de forma constante en una epojé temporal patológica que impediría toda relación con el tiempo en la constitución del sujeto. La apuesta por la presencia a sí de la experiencia presente como única forma posible de experiencia, el principio de la identidad de la experiencia, por así decir - esto es, propiamente hablando, la ipseidad- fundamentaría la violencia propia de la filosofía occidental. En este sentido, Derrida es claro: "Al no pensar lo otro, no tienen el tiempo. Al no tener el tiempo, no tienen la historia. La alteridad absoluta de los instantes, sin la que no habría tiempo, no puede producirse en la identidad del sujeto o del existente. Aquélla viene al tiempo por el otro [...] Incapaces de responder a lo otro en su ser y en su sentido, fenomenología y ontología serían, pues, filosofías de la violencia"66.

Casi cuarenta años después, esta crítica a la violencia originaria de la presencia en la filosofía occidental culmina en la crítica a la bestialidad o animalidad intrínseca del Logos. Esto es, en la crítica a la definición misma de lo humano como "animal racional". A propósito de un comentario a Diferencia y Repetición de Deleuze 67 en su seminario de 2001 La bete et le souverain, Derrida hace suyo el discurso de la bestialidad -bêtise, y no bête, como categorías propias de lo humano y diferentes del animal- del pensamiento occidental. En un principio, esta bestialidad del logos consistiría en el deseo o voluntad impositivos y tajantes de una inteligencia exacta y precisa en la creación de sus conceptos y categorías, en última instancia, en delimitaciones o definiciones como imposición esencialista de los artículos definidos. Se trata, por tanto, de la función mistificante del lenguaje de la presencia: "La $\mathrm{S}$ es $\mathrm{P}$, en el mismo artículo definido, El o La, es siempre bestialidad, definición de la bestialidad. La bestialidad es tanto definitoria como definida. Es lo que quiere decir, sin duda, Flaubert cuando declara que concluir, parar, terminar y definir, con-

ca a la que siempre abocan sus escritos sobre el movimiento de la différance en la constitución de sí. Para una exposición sistemática del Aion remitimos a Cacciari, M., Dell'Inizio, Milano, Adelphi Editore, 1990, pp. 235-303, Cacciari, M., Della Cosa Ultima, Milano, Adelphi Editore, 2004, Deleuze, G., Logique du sens, Paris, Les Éditions de Minuit, 1969, pp. 83-97 y 105-112, y Negri, A., El Poder Constituyente. Ensayo sobre las alternativas de la modernidad, Madrid, Ensayo, 1994, pp. 10-60.

66 Derrida, J., "Metafísica y Violencia", p. 124.

67 Deleuze, G., Différence et répétititon, Paris, Presses Universitaires de France, 1968. 
cluir parando y señalando categóricamente una definición, es un signo de bestialidad [...] Sí, la bestialidad consiste en querer concluir"68. No hay cierre, en el sentido de closure, de cualquier tipo, que no sea una pura bestialidad. En lo que a nuestra lectura se refiere, no hay definición de lo humano que no sea una pura bestialidad. Razón por la cual todo humanismo, incluido el humanismo à venir de Merleau Ponty, no es sino una pura bestialidad.

Como condición de posibilidad misma de este deseo de definición, de este "mismo deseo de inteligencia que es la bestia", sitúa Derrida la noción de una libertad del sujeto autónoma y soberana en camino hacia la constitución de su propia ipseidad: "Por 'ipseidad', sobreentiendo, por tanto, un 'yo puedo', o al menos el poder que se da a sí mismo la ley, su fuerza de ley, su representación de sí, la reunión soberana que se reapropia de sí en la simultaneidad del ensamblaje o de la asamblea, del estar-juntos, del 'vivir-juntos"'69. Sea como Eleutheria (libertad, propiamente hablando) o como Exousía (licencia o libertinaje), las conclusiones derridenanas son claras. La libertad como facultad de un poder hacer, de tomar una decisión, 70 es la condición irrecusable de la autodeterminación del "sí mismo": "nada de libertad sin ipseidad, y vice versa, nada de ipseidad sin libertad" 71 . Frente a esta libertad soberana, voluntarista y autárquica como conceptualización directamente relacionada con la noción de Kratos, Derrida intentará alumbrar el horizonte de una nueva libertad pre-subjetiva o pre-crática (en terminología levinasiana an-árquica)

68 Derrida, J., La bête et le souverain I, p. 220. Y un poco más adelante: "Le savoir est souverain, il est de son essence de vouloir être libre et tout puissant, de s'assurer le pouvoir et l'avoir, la possession et la maîtrise de son objet", Derrida, J., La bête et le souverain I, p. 376.

69 Derrida, J., Voyous. Deux essais sur la raison, Paris, Éditions Galilée, 2003, p. 30.

${ }^{70}$ La referencia a la obra de Carl Schmitt, a cuya discusión dedica Derrida la mayor parte de su Políticas de la amistad, nos parece aquí nítida. Pero esta referencia no debería disminuir la verdadera radicalidad de la crítica derrideana. En realidad, la radicalidad de su lectura no reside en el reconocimiento de la bestialidad de un sujeto soberano que para constituirse en su ipseidad, esto es, en su autoreconocimiento frente a los demás, ejerce una libertad entendida como autonomía de la voluntad, esto es, como decisión. La trágica lógica del suplemento que también actúa aquí nos encamina al planteamiento de un problema previo. La tragedia reside en que es precisamente la dación temporal del otro que pre-constituye nuestra apertura al mundo la que hace posible la necesidad del suplemento decisional. El otro, dándonos el tiempo de nuestra libertad, nos capacita para auto-constituirnos soberanos. En realidad es el otro el que nos da la capacidad de soberanía, la capacidad de poder y, puesto que el poder es un concepto fundamentalmente potencial en sí (interrelación indeclinable de puissance y pouvoir), la soberanía misma. Es esta nuestra responsabilidad para con él. No una responsabilidad por su cuidado, ¡sino por el nuestro! Pero si es la dación del tiempo del otro lo que nos abre al decisionismo de la soberanía, será el laberinto de nuestra propia técnica de las mediaciones la que nos abrirá hacia un intento de libertad que, sin poder eludir la suplementariedad de la técnica, intente ir más allá de la misma. Más allá de lo humano en sí. A diferencia de la postura mantenida por Critchley y el propio Derrida, aquí sostenemos que la decisión no pertenece al ni abre el ámbito de lo político. La decisión no es política. No es praxis.

71 Derrida, J., Voyous, p. 45. 
como condición de posibilidad de la apertura a la otredad y, por tanto, al tiempo: "La libertad se extiende a todo lo que aparece en lo abierto. Se extiende al acontecimiento de todo lo que, en el mundo, y de entrada en el 'hay' del mundo, viene a la presencia"72. Esta nueva conceptualización de la libertad sería, pues, una libertad anterior y más profunda en la constitución del sujeto. Antes incluso que la libertad propia de un sujeto soberano ya constituido y capaz de ejercer su soberanía, es necesario que exista la libertad pre-árquica que posibilite la constitución misma de la ipseidad del sujeto mediante la influencia de la otredad.

Ahora bien, para Derrida, el hecho mismo de que sea necesario postular esta libertad pre-árquica como condición de posibilidad de la constitución de la ipseidad, implica necesariamente la imposibilidad de una autoposición "natural" originaria del "sí mismo", razón última de la performatividad propia de toda ipseidad73. Es decir, para Derrida, la necesidad irrecusable de tener que postular esta libertad preárquica supone obligatoriamente una interrupción, una mediación técnica, no natural, un espaciamiento inevitable en la autoposición del sí "mismo" como "sí mismo". Autoposición originaria de una ipseidad previa a la noción de "sujeto" y de "yo". Pero, ¿previa también a la noción de "humano" y de "persona"?

Una vez llegados a este punto debemos dar un pequeño desvío mediante la problematización de las relaciones entre filosofía y política si queremos poder dar respuesta a esta pregunta. Un desvío que nos situará en un corte con el pensamiento de los intérpretes más levinasianos de Derrida respecto a lo político, corte este que nos permitirá, creemos nosotros, separarnos de la concepción levinasiana de la política pero sin salirnos del ámbito de la deconstrucción de la relación entre política por una parte, y filosofía como ontología por otra.

A este respecto, la principal separación que realizaremos de estas interpretaciones del pensamiento de Derrida reside en la consideración de lo político como el ámbito de decisión. En la postura política de los intérpretes más levinasianos de Derrida el momento de la decisión es aquel punto-límite en el que la indecibilidad propia del ámbito ético, vía el mandato incondicional de responsabilidad por el otro, esto es, de respuesta por el otro, debe ser convertida en acción política. Por ello también en este ámbito las condiciones de posibilidad de lo político, la decisión, son

\footnotetext{
72 Derrida, J., Voyous, p. 81.

${ }^{73}$ La performatividad de la ipseidad en el pensamiento derrideano redirige siempre a una cuestión lingüística, tanto en su crítica general al fonocentrismo como en el análisis concreto de la obra de Austin, en especial de su texto Cómo hacer cosas con palabras, cuyo exponente paradigmático es Derrida, J., "Firma, acontecimiento, contexto", Congreso Internacional de las Sociedades de Filosofía de Lengua Francesa, Montreal, 1971, recogido en Derrida, J., Márgenes de la Filosofía, Madrid, Cátedra, 2006, pp. 347-372. Para un estudio en profundidad acerca de los procesos concretos de mediación lingüística en la determinación de subjetividades identitarias en la obra de Derrida existe una desbordante discusión académica a propósito de las filosofías queer, de género y postfeministas de los años 80 y 90 a las que remitimos directamente.
} 
simultáneamente sus condiciones de imposibilidad: la indecibilidad de lo ético. Pero esto reduce las posibilidades de la deconstrucción a la de mera reflexión filosófica sobre lo político.

Si bien la deconstrucción del humanismo y de la filosofía como ontología habría logrado cortocircuitar la bestialidad de la razón propia de las posturas que presuponían una determinada ontología como fundamento directo de la acción política, también habrían conducido a la deconstrucción a un punto de parálisis práctica de la política al haber limitado la consideración de lo político al ámbito de una decisión por siempre cortocircuitada del discurso ontológico.

El principal problema radica en que el ámbito de lo político no puede ser reducido, como el mismo Derrida ya afirmaba, a un momento de sucesión cronológica del ámbito ético, del imperativo incondicional de responsabilidad por el otro que hace imposible la decisión, sino que debe ser analizado en su conjunto desde el punto de vista de la estructura temporal del à venir 74 . Una estructura que llevada hasta sus límites evidencia que el ámbito político ya está dado de forma previa a toda decisión, que es una cuestión de praxis intersubjetiva previa a toda decisión y que, a su vez, es la condición de posibilidad de que pueda aparecer el otro como mandato incondicional de responsabilidad. Por ello la imposibilidad de una decisión como deducción lógica consistente no es necesariamente una incapacidad política de la deconstrucción, sino la posibilidad misma de la responsabilidad por el otro. A diferencia de las lecturas más levinasianas de la obra de Derrida, lo que estamos planteando aquí es la primacía de la política de la deconstrucción, y ya no de la ética como mandato incondicional.

Ahora bien, al haber considerado la política como praxis intersubjetiva previa al ámbito de la decisión y del mandato incondicional por la responsabilidad del otro, las categorías propias de lo político serán aquellas que se evidencien como condición de posibilidad de la decisión y de la ética. Concretamente, todas aquellas prácticas intersubjetivas que consciente o inconscientemente utilizamos para concebir al otro como à venir, junto a todas aquellas estructuras culturales que dependen de la estructura del otro como à venir para poder ser realizadas. Esto es, todas aquellas prácticas comunes, todo el hacer común que únicamente puede conformarse desde la apertura del otro como à venir. En última instancia, cualquier sistema práctico no

\footnotetext{
${ }^{74}$ Afirma Derrida: "'If I conduct myself particularly well with regard to someone, I Know that it is to the detriment of an other; of one nation to the detriment of another nation, of one family to the detriment of another family, of my friends to the detriment of other friends or non-friends, etc. This is the infinitude that inscribes itself within responsibility; otherwise there would be no ethical problems or decisions. And this is why undecidability is not a moment traversed and overcome. Conflicts of duty, and there is only duty in conflict, are interminable and even when I take my decision and do something, undecidability is not an end [...] There is politicization or ethicization because undecidability is not simply a moment to be overcome by the occurrence of the decision", Derrida, J., Remarks on Deconstruction and Pragmatism", en Mouffe, Ch. (ed), Deconstruction and Pragmatism, p. 89.
} 
cerrado que permita un hacer común pre-reflexivo y cuya condición de posibilidad es la apertura que dé acceso al otro.

Una posición de la primacía política de la deconstrucción que permitiría una con-frontación, aún por realizar, con todas aquellas filosofías políticas, que basadas en la noción deleuziana de agenciamiento, presuponen el hacer-común en redes o rizomas siempre abiertos como la esencia de lo político en su primacía respecto a la ontología. Una primacía de la política que entiende esta como el hacer-se(r) en común con la apertura irreductible de este hacer-se(r) que permite la estructura del $\grave{a}$-venir. En última instancia, es la apertura de esta praxis intersubjetiva pre-reflexiva, de esta técnica del hacer-se(r) en común apertura la que permite que la estructura del à venir permita la aparición del otro como mandato incondicional de responsabilidad. Y es desde esta concepción técnica de la política como podremos dar una respuesta a la cuestión de lo humano.

Una intersubjetividad, pues, técnica, y esto es lo importante, no exclusivamente lingüística o comunicacional al modo tanto de Habermas como de Rorty. Pues lo que aquí estamos sosteniendo es que la política no puede ser ni el ámbito de la decisión ni el conflicto de doxas, ya que ambas posturas no son sino visiones dependientes de un entendimiento soberano de un nosotros ya decidido como animales racionales a través de la separación del resto de seres vivientes mediante el concepto de lo humano. Desde nuestra postura, la política no es un pensar-decidir conjunto de seres racionales. La política es un hacer en común apertura previo a la definición de lo racional. Praxis y techné. Espaciamiento técnico del à venir.

Efectivamente, si la política se entendiera como el conflicto de doxas y la deconstrucción como la simple imposibilidad de someter la doxa a la episteme, el mismo ámbito ético de la deconstrucción quedaría imposibilitado. Una concepción de la deconstrucción que se limitara únicamente a mostrar constantemente la imposibilidad de establecer una auto-fundación del Logos como fundamento, esto es, la imposibilidad de cualquier aspiración de someter la doxa al Logos y de establecer una episteme que faculte para realizar dicho sometimiento, reduciría la deconstrucción a simple crítica filosófica en el sentido kantiano del término. Punto este último que ha sido negado de forma explícita por Derrida en varias ocasiones 75 .

En cambio, desde nuestra postura, y adelantando las conclusiones de este apartado, mantenemos que cuando Derrida afirma que "no hay nada propio de lo humano"76, está haciendo referencia a esta consideración política de la deconstrucción como praxis intersubjetiva de la estructura del à venir, de la différance como praxis

\footnotetext{
75 Afirma Derrida: "Tampoco es una crítica, en un sentido general o en un sentido kantiano. La instancia misma del krinein o de la crisis (decisión, elección, juicio, discernimiento) es, como lo es por otra parte todo el aparato de la crítica trascendental, uno de los "temas" o de los "objetos" esenciales de la deconstrucción", Derrida, J., "Carta a un amigo japonés", en Derrida, J., El tiempo de una tesis. Deconstrucción e implicaciones conceptuales, Barcelona, Proyecto A Ediciones, 1997, p. 25.

76 Derrida, J., La bête et le souverain I, p. 357.
} 
intersubjetiva del hacer-se(r) en común (y asimétrica) apertura, de modo que toda definición de lo humano, que toda ética exclusivamente humana sería la imposición de una violencia de la exclusión propia de toda ontología como sistema cerrado.

A este respecto es importante no confundir la inexistencia de lo propiamente humano por parte de Derrida con la consideración marxista del hombre como aquel que crea y fabrica mediante la técnica sus propios instrumentos de supervivencia de modo que es ese crear técnico el hecho que le define como humano y lo separa, define y delimita respecto del resto del mundo. Esta última posición era la mantenida por el Humanismo à venir de Merleau Ponty77. En el caso de Derrida, al trasladar el hacer-se(r) en común apertura a un ámbito pre-racional, la conclusión necesaria es que el hombre, lo humano como tal, simplemente no existe. Dicho en terminología deleuziana, el hombre como lo no-humano vía la estructura abierta del à venir es capaz de devenir cualquier cosa, de entrar en agenciamiento con cualquier otro ser. Razón por la cual el Otro, esto es, una auténtica Otredad que haga justicia a esta estructura del à venir y a esta concepción de lo político no puede ser la humanidad, no puede ser un Otro previa y violentamente delimitado a través de la categoría de lo humano, y mucho menos puede intentar rehabilitarse la Otredad absoluta a través de la figura del hijo como intentan algunas de las lecturas más neoconservadoras y reaccionarias de la obra de Levinas ${ }^{78}$. Una auténtica Otredad que haga Justicia a esta concepción radical y anti-logocéntrica de la política y la deconstrucción debe situarse antes, o más allá, de la conceptualización de lo humano. Antes de la definición de lo humano como instrumento de medida.

A este respecto, la bestialidad de lo humano radicaría en considerar al hombre como el único ser que se mide a sí mismo. Este es el problema. Tanto el infinito como la noción de lo humano, ya sea en su forma ético levinasiana o en la ontológica, no son más que unas necesidades correlativas para medir la finitud del hombre, por la vía de la trascendencia de la otredad. Frente a una consideración de lo humano como medida y exclusión, la deconstrucción de lo humano debe trabajar siempre en pro de la des-mesura y el agenciamiento abierto con los hacer-se(r) comunes. Es momento, pues, de proceder con Derrida a la deconstrucción de lo humano.

Por una parte, Derrida comienza considerando la concepción de lo humano en su diferencia con la inmediatez de los dioses y la relativa inmediación de los animales "pobres en mundo", en su grado de mediación protética. Lo humano, si se

\footnotetext{
77 "Marx distingue radicalmente la vida humana de la vida animal porque el hombre crea los medios de su vida, su cultura, su historia y demuestra así una capacidad de iniciativa que constituye su originalidad absoluta", Merleau Ponty, M., Humanismo y Terror, p. 12.

78 Nos referimos a los continuos intentos de recuperación de las partes más desafortunadas de la obra de Levinas, cuya última versión en el ámbito nacional tal vez sea el que Laura Llevadot ha reproducido. Cfr. Llevadot, L., "No hay mundo común: Jacques Derrida y la idea de comunidad", Isegoría. Revista de Filosofía Moral y Política, no 49, 2013, pp. 549-566.
} 
puede aún hablar de algo así, sería el auto-constituirse mismo de la mediación técnica desde el espaciamiento pre-originario de la otredad radical, de lo "monstruosamente otro, del otro irreconocible", esto es, del otro irreconocible siquiera como otro yo. Ahora bien, afirma Derrida que "lo 'irreconocible', diría de manera un poco elíptica, es el comienzo de la ética, de la Ley, y no de lo humano"79. En otras palabras, la mediación técnica del espaciamiento originado por la otredad es el origen mismo de la Ética y de la Ley, pero no de lo humano.

Ahora bien, la ruptura de la ipseidad del yo propia de toda deconstrucción no puede no problematizar cuanto menos el sentido de lo humano: "Romper con toda identificación de una imagen de sí, con todo ser vivo parecido [es romper] con toda fraternidad o toda proximidad humana, con toda humanidad. Este lugar del Otro, ¿no debe ser a-humano?"80. Así pues, este otro no humano, esta "divinianimalidad" señalada por Derrida como "el referente quasi transcendental, el fundamento excluido, prescrito, denegado, dominado, sacrificado de lo que él funda, a saber el orden simbólico, el orden humano, la ley, la justicia" 81 es a su vez, como siempre en toda deconstrucción, la imposibilidad misma de que lo humano se auto-imponga en su ipseidad vía suplemento técnico-protético. Una vez aquí, lo que conviene señalar es que la salida de sí levinasiana es convertida por Derrida en su comentario a Paul Celan en un auténtico intento de "salida fuera de lo humano".

Para este último, al menos en la lectura derrideana, el arte, la técnica mediadora por excelencia, esa técnica que en tanto que Ética o Ley Derrida ya ha distinguido de lo humano, sería prioritariamente "unheimlich", palabra traducida al francés como "étrange" o "dépaysant". Un arte donde "se encontrarían en su casa estas cosas aparentemente inhumanas", y entre ellas, de forma primordial, "los autómatas o las marionetas" 82 . Los autómatas y las marionetas, pues, como lo aparentemente inhumano. Una referencia directa al teatro, tanto griego como vanguardista, a las máscaras de la constitución del personaje, de la persona misma, es situada por Derrida-Celan en el corazón mismo de lo aparentemente inhumano. Del arte aparentemente in-humano.

Pero es que, además, precisa Derrida, esta ipseidad, esta autoposición del símismo, del Selbst que estamos constantemente analizando, "no es todavía ni un 'Yo' ni un individuo, ni un nosotros ni una comunidad, es un 'quien' ante todo 'Yo', todo individuo, toda persona, todo nosotros y toda comunidad" 83 . En otras palabras, tanto la otredad como la ipseidad son indecibles pre-originarios al origen mismo tanto de "lo humano" como de "la persona". Razón por la cual, al menos en

\footnotetext{
79 Derrida, J., La bête et le souverain I, p. 155.

80 Derrida, J., La bête et le souverain I, p. 177.

81 Derrida, J., La bête et le souverain I, p. 177.

82 Derrida, J., La bête et le souverain I, p. 350.

83 Derrida, J., La bete et le souverain I, p. 355. (El subrayado es nuestro).
} 
apariencia, la deconstrucción de la ipseidad en su llegada a un "quien" que no es "yo" como incondicional archioriginario de la différance implicaría una salida tanto de "lo humano" como de "la persona". Ni la definición de lo humano como "animal racional", ni la constitución del yo como persona -ya sea esta entendida como construcción del personaje (esto es, como máscara-suplemento), como síntesis temporal de la narratividad del yo, como forma substancial, o como continua configuración inter-subjetiva sin fin- son para Derrida configuraciones previas al "quien" que encamina hacia la ipseidad del "yo" a la vez que lo imposibilita. El "quien" no sería ni hombre ni persona. Estaríamos, por tanto, completamente fuera de lo humano y lo personal. En este punto afirma Derrida que "la esencia del hombre" si es que todavía se puede hablar de algo así sin ser traicionados por el mismo lenguaje que habla con o sin "yo", su Grundzug, "es este ser extraño a todo lo que se puede identificar como familiar, reconocible, etc. Lo propio del hombre sería, en suma, esta manera de no estar seguro en su propia casa" 84 .

Es en este punto cuando se vuelve a instaurar una tensión con las lecturas más levinasianas de Derrida. Pues alguien podría perfectamente plantearse si Derrida está proponiendo lo humano nuevamente como salida de sí levinasiana. Frente a estas lecturas, la posición mantenida por nosotros es que no es así. Nuestra lectura de la crítica de Derrida a lo humano no es aquella concepción de lo inhumano como salida propia de un concepto de lo humano definido según el humanismo soberano o el humanismo del otro sino, más allá incluso, el planteamiento de si es posible una salida de lo humano en tanto que mediación técnica sin fin propia de la política como praxis del hacer-se(r) en común apertura. El problema no es, pues, el uso de la mediación técnica para salir de un humanismo soberano tanto de la presencia inmediata como del à venir revolucionario. La cuestión es si es posible salir de la mediación técnica propia de lo político como praxis, cómo salir de la lógica del suplemento desde la misma lógica técnico-mediática del suplemento. ¿Hasta qué punto está abierta la constitución político-temporal del à venir? ¿Es posible llegar a salir de la propia estructura político temporal? ¿De la praxis temporal? Salir no ya de una concepción preestablecida de lo humano, sino de cualquier posibilidad de llegar a concebir una estructura pre-ontológica que sea usada para diferenciar-(nos) unos de otros.

Este es un problema que, si bien no quedó resuelto, Derrida, a nuestro modo de ver no eludió, y trató por extenso en su Papel Máquina ${ }^{85}$. Es aquí donde, antes que

84 Derrida, J., La bête et le souverain I, p. 357.

85 Es en este texto donde Derrida se pregunta abiertamente: “¿Podremos pensar, lo que se llama pensar, de una sola y misma vez, tanto lo que sucede (a esto se lo denomina acontecimiento) como, por otra parte, la programación calculable de una repetición automática (a esto se le denomina máquina)? [...] Hoy nos parecen antinómicos. Antinómicos porque se considera que lo que sucede debería conservar cierta singularidad no programable, por consiguiente, incalculable. Se considera que un acontecimiento digno de ese nombre debería no ceder o no reducirse a la repetición", Derrida, J., Papel 
como oposición a la lógica del hombre máquina mecánico, la salida de lo humano que busca Derrida debe realizarse desde la lógica del no-hombre-máquina maquínico (en referencia a las máquinas desiderantes deleuzianas), pues el no-hombremáquina maquínico sería aquella noción tecno-protética de la posibilidad de lo nohumano; es decir, la consideración de la absoluta maleabilidad de la misma estructura del à venir mediante el agenciamiento en común apertura con la Otredad nohumana. Tal y como postulaban Deleuze, Guattari y Negri, una consideración de lo político como absolutamente previo al Ser, a sus estructuras existenciales y/o existenciarias, y a sus condiciones de posibilidad de cualquier tipo. La salida de lo humano, pues, como posibilidad o problematización al menos de la salida de toda condición de posibilidad de algo. Es llamando a la venida de un acontecimiento maquínico, no calculable, no cronológico, no presente a sí mismo, sin condiciones de posibilidad, como podríamos salir de lo humano. Una salida de lo humano que sería justamente salida de lo humano como "animal racional" en tanto que autoposición bestial de la razón.

\section{Sin concluir: Apertura radical del común hacer el mundo con toda otra maquínica entidad}

Si bien ya han sido planteadas diversas críticas a la excesiva humanidad de la ética levinasiana apoyándose en su relativo olvido del resto de seres vivientes concretamente los animales- 86 problematizaciones estas sobre la relación lo humano y lo animal en las que intervino el propio Derrida ${ }^{87}$; el objetivo de estas reflexiones finales no será pormenorizar en las posibilidades de la relación hombre-animal, en terminología deleuziana de las formas de devenir animal, sino más allá o más acá incluso, plantear la posibilidad de relaciones, propiamente maquínicas, entre sistemas radicalmente abiertos, esto es, entre sistemas no definidos unívocamente con la capacidad de alterar sus propias condiciones de posibilidad a través de la interac-

\footnotetext{
Máquina, p. 32. Y finalmente concluye que "si no llega más que lo que ya es posible, por consiguiente, anticipable y esperado, eso no produce un acontecimiento. El acontecimiento sólo es posible si procede de lo imposible. Acontece como la venida de lo imposible, allí donde un 'quizá' nos priva de toda seguridad y deja el porvenir al porvenir”, Derrida, J., Papel Máquina, p. 251.

86 A este respecto son textos paradigmáticos a los que remitimos para una discusión en profundidad sobre la relación entre lo humano y lo animal Llewelyn, J., "Am I Obsessed by Bobby?", en Bernasconi, R. \& Critchley, S. (eds.), Re-Reading Levinas, Bloomimngton, Indiana University Press, 1991, pp. 234-245, Wolfe, C. (ed.), Zoontologies: The Question of Animal, Minneapolis, University of Minnesota Press, 2003 y Guenther, L., "Le flair animal: Levinas and the Possibility of Animal Friendship", PhaenEx 2, n 2, 2007, pp. 216-238.

87 Además de los seminarios ya analizados de La bête et el souverain, Derrida problematizó de forma explícita la posibilidad de una relación humano-animal en Derrida, J., "The Animal That Therefore I Am (More to Follow)", en Critical Inquire, vol. 28, n 2, 2002, pp. 369-418.
} 
ción con otros sistemas radicalmente abiertos. En otras palabras, antes que intentar auspiciar las posibilidades del devenir desde lo humano hasta el agenciamiento con la vida animal, lo que buscamos es dar un marco de referencia a la posibilidad de la relación de lo propiamente no-humano con la vida artificial.

La cuestión se vuelve fundamental cuando vemos el interés paralelo de todo humanismo por los artefactos mecánicos. Con la intención de dar ejemplo paradigmático de cómo este interés por los autómatas mecánicos o los hombres máquina, en lugar de ser una consideración contraria al humanismo, se configura históricamente como uno de sus puntos fundamentales traeremos a colación antes que el ya suficientemente conocido "hombre máquina" de LaMettrie, la pasión por los artilugios mecánicos de uno de los primeros fundadores del Humanismo, Marsilio Ficino. A este propósito, Chastel nos informa que "en 1475 Ficino examinó en Florencia una máquina articulada, un artilugio de autómatas, que le pareció un excelente símbolo del orden cósmico: 'Figuras de animales hechas solidarias de una sola bola, por un sistema de equilibrio, se movían diversamente en función de ésta: unos corrían a la izquierda, otros a la derecha, hacia arriba o hacia abajo, otros se levantaban, se bajaban; unos rodeaban a otros; algunos, en fin, golpeaban a otros. Se oían también trompetas y cuernos, el canto de los pájaros y otros fenómenos del mismo género que se producían en gran número, por el sólo movimiento de esa única bola'. Toda la época tuvo pasión por los juguetes mecánicos, máquinas de sorpresas, que propiamente parecen maravillas, miracula; el interés de Ficino por el 'tabernáculo' del fabricante alemán demuestra en qué sentido se orientaba entonces la filosofía de los autómatas. Representan el mundo y testimonian el poder del hombre que lo domina. Son idénticos a la naturaleza, porque es también ella un mecanismo perfectamente articulado, donde el detalle de las formas cuenta menos que la solidaridad y el movimiento, es decir, el gran juego del conjunto" 88 .

Desde este doble perverso, esta obsesión continuada del humanismo por los sistemas mecánicos perfectamente cerrados llama a la problematización del humanismo y de lo humano desde un punto de vista propiamente maquínico, de la capacidad de devenir máquina y entrar en agenciamiento con la posibilidad de la inteligencia y/o vida artificial. Para ello, recordamos el acceso levinasiano al rostro del otro se realizaba a través del lenguaje, postura esta que actualizada a la radicalización de la crítica a lo humano establecería que el acceso a la Otredad maquínica vía el interface se debería realizar a través del código, de la pro-gramma-ción. Esta es una nueva problemática que desvía el entendimiento del humanismo como zoopolítica propia de las reflexiones de Sloterdijk ${ }^{89}$ hacia una biopolítica de los sistemas propias de los sistemas abiertos en las Smart Cities.

88 Chastel, A., Arte y humanismo en Florencia en la época de Lorenzo el Magnifico, Madrid, Cátedra, 1982, p. 216.

89 "Desde que el Polikos, desde que la Politeia son discursos que, en el mundo, hablan de la comuni- 
Desde nuestro punto de vista, la crítica radical al humanismo ya no sólo debería ocuparse de mostrar y evidenciar ese proceso de domesticación donde todo lo comúnmente adjudicado por las almas supuestamente humanitarias a lo "monstruoso no humano" (asesinato, incesto, terrorismo, pederastia, violación) estaría exclusivamente orientado a la legitimación de la excomunión del sujeto agente de tales hechos de la esfera de lo humano. Más allá de mostrar la violencia del humanismo como medida de de-limitación de los grupos políticos propiamente humanos, la crítica radical a lo humano deberá encaminarse a la instauración de nuevas praxis nohumanas para el establecimiento de relaciones propiamente políticas no únicamente con los sujetos o agentes de una supuesta comunidad, sino también con todos los sistemas o estructuras abiertas que confluyen en un hacer-se(r) en común al modo de la haecceitas de Duns Scoto.

Esto es, una construcción de la ética de lo no-humano que entre en agenciamiento con todos los sistemas abiertos que inter-actuan en la con-creación de la realidad: Hombres, máquinas, animales, sistemas culturales, medio ambiente, economía, sistemas informáticos. Un rizoma de sistemas en interacción sin mesura que conciban la plena disolución del yo y de lo humano mismo en nada más que un sistema abierto de relaciones capaces de cambiar las propias condiciones de posibilidad más allá aún de la estructura del à venir.

Como ya afirmaba David Hume, "puedo aventurarme a afirmar que todos lo demás seres humanos no son sino un haz o colección de percepciones diferentes, que se suceden entre sí con rapidez inconcebible y están en un perpetuo flujo y movimiento $[\ldots]$ ¿qué es entonces lo que nos induce con tanta intensidad a asignar una identidad a estas percepciones sucesivas, y a creernos en posesión de una existencia invariable e ininterrumpida durante toda nuestra vida?" 90.

\section{Referencias bibliográficas}

AA. VV.: Les Cahiers de la nuit surveillée. Lagrasse: Verdier, 1984.

Bernasconi, R. \& CRitchley, S. (eds.): Re-Reading Levinas, Indiana University Press, Bloomimngton, 1991

Cacciari, M.: Dell'Inizio. Milano: Adelphi Editore, 1990.

Cacciari, M.: Della Cosa Ultima. Milano: Adelphi Editore, 2004.

dad de los hombres como si se tratara de un parque zoológico que fuera a la vez un parque temático, la conducta de los hombres en parques o ciudades deberá aparecer, en adelante, como un problema zoopolítico. Lo que se presenta como una reflexión sobre política, es en realidad una reflexión fundamental sobre las reglas de manejo de un Parque Humano", Sloterdijk, P., Reglas para el Parque Humano. Una respuesta a la 'Carta sobre el Humanismo' (El discurso de Elmau), publicado en Die Zeit, 1999, p. 16.

90 Hume, D., Tratado de la Naturaleza Humana, vol. I, Barcelona, RBA Coleccionables, 2002, p. 196. 
Chalier, C.: Por una moral más allá del saber, Kant y Levinas. Madrid: Caparrós editores, 2002.

Chastel, A.: Arte y humanismo en Florencia en la época de Lorenzo el Magnifico. Madrid: Cátedra, 1982.

Colette, J.: "Lévinas et la phénoménologie husserlienne". En AA. VV., Les Cahiers de la nuit surveillée. Lagrasse: Verdier, 1984, pp. 19-36.

Critchley, S.: The Ethics of Deconstruction: Derrida and Levinas, Edinburgh University Press, Edinburgh, 1992.

Deleuze, G.: Différence et répétititon. Paris: Presses Universitaires de France, 1968.

Deleuze, G.: Logique du sens. Paris: Les Éditions de Minuit, 1969.

Deleuze, G. \& Guattari, F.: Mil mesetas. Capitalismo y esquizofrenia. Valencia: Editorial Pre-Textos, 2004.

DERRIDA, J.: La escritura y la diferencia. Barcelona: Editorial Anthropos, 1989.

DERRIDA, J.: La voz y el fenómeno: introducción al problema del signo en la fenomenología de Husserl. Valencia: Pre-textos, 1995.

DerridA, J.: Dar el tiempo I. La moneda falsa. Barcelona: Paidós Ibérica, 1995.

DERRIDA, J.: El tiempo de una tesis. Deconstrucción e implicaciones conceptuales, Proyecto A Ediciones, Barcelona, 1997.

DerridA, J.: Políticas de la amistad. Madrid: Trotta, 1998.

DERRIDA, J.: Introducción a El origen de la geometría. Buenos Aires: Manantial, 2000.

DerRIDA, J.: Papel Máquina. Madrid: Editorial Trotta, 2003.

DERRIDA, J.: De la gramatología. Buenos Aires: Siglo Veintiuno Editores, 2003.

DERRIDA, J.: Espectros de Marx. El estado de la deuda, el trabajo del duelo, y la nueva internacional. Barcelona: Editorial Trotta, 2003.

Derrida, J.: Voyous. Deux essais sur la raison. Paris: Éditions Galilée, 2003.

Derrida, J.: "The Animal That Therefore I Am (More to Follow)", Critical Inquire, vol. $28, n^{\circ} 2,2002$, pp. 369-418.

Derrida, J.: "Firma, acontecimiento, contexto". En: Derrida, J., Márgenes de la Filosofía. Madrid: Cátedra, 2006, pp. 347-372.

DERrida, J.: Séminaire La bête et le souverain I. Paris: Éditions Galilée, 2008.

DERridA, J.: Séminaire La bête et le souverain II. Paris: Éditions Galilée, 2010.

Fornet, R.; Gómez, A.: "Filosofía, Justicia y Amor. Entrevista con Emmanuel Levinas". Concordia, 3, 1983, pp. 59-73.

GENET, J.: El niño criminal. Madrid: Errata Naturae Editores, 2009.

GreISCH, J.: "Heidegger et Levinas interprètes de la facticité". En Levinas, E., Positivité et transcendance: suivi de Lévinas et la phénoménologie. Paris: PUF, 2000, pp. 181-207.

Guenther, L.: "Le flair animal: Levinas and the Possibility of Animal Friendship", PhaenEx 2, no 2, 2007, pp. 216-238. 
Guillot, D. E.: “Introducción”. En: Levinas, E., Totalidad e infinito. Ensayo sobre la exterioridad. Salamanca: Sígueme, 1977, pp. 13-45.

HAAR. M.: “L'Obsession de l'autre. L'éthique comme traumatisme”. En: AA.VV., Cahier de l'Herne. Emmanuel Levinas. Paris: Éditions de l'Herne, 1991, pp. 444-453.

HÄGglund, M.: “The Radical Evil of Deconstruction. A Reply to John Caputo”, Journal for Cultural and Religious Theory, n. 11.2, 126-150.

HAYAT, P.: "La philosophie entre totalité et transcendance". En Altérité et transcendance. Paris: Fata Morgana, 1995, pp. 9-26.

Hume, D., Tratado de la Naturaleza Humana, vol. I, RBA Coleccionables, Barcelona, 2002.

HuSSERL, E.: La crisis de las ciencias europeas y la fenomenología trascendental. Barcelona: Crítica, 1991.

LefeBvre, H.: De lo rural a lo urbano. Barcelona: ediciones península, 1971.

Lehmann, H.-T.: Postdramatic Theater. London: Routledge, 2006.

Levinas, E.: "Le Moi et la Totalité". Revue de Métaphysique et de Morale, 1954, pp. 353-373.

LevinAs, E.: “La philosophie et 1'idée de l'Infini”. Revue de Métaphysique et de Morale, 1957, pp. 241-261.

LEVINAS, E.: “Transcendance et hauteur". Bulletin de la Société Française de Philosophie, 1962, pp. 107-109.

Levinas, E., Nouvelles lectures talmudiques, Paris, Minuit, 1968.

LÉvinAs, E: "La proximité". Archives de Philosophie, 34, 1971, pp. 373-391.

LEVINAS, E.: L'Humanisme de l'autre homme. Paris: Fata Morgana, 1972.

Levinas, E.: Difficile liberté: essai sur le judaïsme. Paris: Albin Michel, 1976.

LEVINAS, E.: Totalidad e infinito. Ensayo sobre la exterioridad. Salamanca: Sígueme, 1977.

Levinas, E.: Autrement qu'être. Au d'elá de l'essence. La Haya: Nijhoff, 1978.

LEVINAS, E.: Le temps et l'autre. Paris: Fata Morgana, 1979.

Levinas, E.: De l'évasion. Montpellier: Fata Morgana, 1982.

LEvinAS, E.: "Entretien avec Emmanuel Lévinas". Revue de Métaphysique et de Moral, 1985, pp. 296-310.

LEvinas, E.: Entre nosotros. Ensayos para pensar en otro. Valencia: Pre-Textos, 1993.

LEVINAS, E.: “Quelques réflexions sur la philosophie de 1'hitlérisme”. En: Levinas, E., Les imprévus de l'histoire. Paris: Fata Morgana, 1994, pp. 27-41.

Levinas, E.: Liberté et commandement. Paris: Fata Morgana, 1994.

LeVINAS, E.: Dios, la muerte y el tiempo. Madrid: Cátedra, 1994.

LeVInAS, E.: Altérité et trascendance. Paris: Fata Morgana, 1995.

Levinas, E., Positivité et transcendance: suivi de Lévinas et la phénoménologie. Paris: PUF, 2000. 
Levinas, E.: De Dios que viene a la idea. Madrid: Caparrós, 2001.

LleVADOT, L.: "No hay mundo común: Jacques Derrida y la idea de comunidad", Isegoría. Revista de Filosofía Moral y Política, no 49, 2013, pp. 549-566.

MARION, J. L.: "D'autrui à l'individu". En: Levinas, E., Positivité et trascendance. Paris: Fata Morgana, 1995, pp. 287-308.

Mann, T.: Doktor Faustus. Barcelona: Edhasa, 2009.

Merleau-Ponty, M.: Humanismo y Terror. Buenos Aires: La Pléyade, 1995.

Mouffe, CH. (ed.): Deconstruction and pragmatism, London and New York, Routledge, 1996.

Negri, A.: El Poder Constituyente. Ensayo sobre las alternativas de la modernidad. Madrid: Ensayo, 1994.

Petitdemange, G.: "L'un ou l'autre. La querelle de l'ontologie: HeideggerLévinas”. En: AA. VV., Les Cahiers de la nuit surveillée. Lagrasse: Verdier, 1984, pp. 37-49.

Ramírez, M. T.: "Merleau-Ponty y el giro político de la filosofía del siglo XX". Astrolabio. Revista Internacional de Filosofía, 14, 2013, pp. 53-68.

Renaut, A.: "Levinas et Kant". En: Levinas, E., Positivité et trascendance. Paris: Fata Morgana, 1995, pp. 89-104.

Rolland, J.: "Subjectivité et an-archie". En: AA. VV., Les Cahiers de la nuit surveillée. Lagrasse: Verdier, 1984, pp. 177-181.

SlOterdiJK, P.: Reglas para el Parque Humano. Una respuesta a la 'Carta sobre el Humanismo' (El discurso de Elmau), publicado en Die Zeit, 10 de septiembre de 1999.

Waldenfels, B.: "La responsabilité. En: Levinas, E., Positivité et trascendance. Paris: Fata Morgana, 1995, pp. 259-283.

Wolfe, C. (ed.): Zoontologies: The Question of Animal, University of Minnesota Press, Minneapolis, 2003.

Zizek, S.: A propósito de Lenin. Política y subjetividad en el capitalismo tardío. Buenos Aires: Parusía, 2003.

Jorge León

Universidad San Jorge (Zaragoza)

jleon@usj.es

Julia Urabayen

ICS Universidad de Navarra

jurabayen@unav.es 